\section{Research Article}

(C) 2021 Svetlana Kravchuk. This is an open access article licensed under the Creative Commons Attribution-NonCommercial 4.o International License (https://creativecommons.org/licenses/by-nc/4.o/)

Received: 29 October 2020 / Accepted: 12 December 2020/ Published: 17 January 2021

\title{
The Relationship between Psychological Resilience and Tendency to Forgiveness
}

\author{
Svetlana Kravchuk \\ PhD in Psychology, Associate Professor, \\ Senior Researcher, Laboratory of Communication Psychology, \\ Institute of Social and Political Psychology, \\ National Academy of Pedagogical Sciences of Ukraine, \\ 52a, Sichovykh Striltsiv Str., Kyiv, 04053, Ukraine
}

DOI: https://doi.org/10.36941/ajis-2021-0oo2

\begin{abstract}
In this study the relationship between tendency to forgive and psychological resilience was studied and the factors of psychological resilience were investigated. The participants were 615 Ukrainian students (317 women; 298 men). Psychological Resilience Scale (PRS-11), Trait Forgivingness (dispositional) Scale, The scale of psychological well-being, Freiburg Personality Inventory, Hardiness Test, Mental Health Outcome Measures (Depression and Anxiety (BSI-12)), Overall Self-efficacy Scale were applied. Reliability of measures was assessed by adopting McDonald's omega. Pearson's correlation coefficient to test the features of the relationship between tendency to forgive and psychological resilience was investigated. The multiple regression analysis for the factors of psychological resilience was performed. The higher level of tendency to forgiveness is connected with higher level of psychological resilience. The higher level of psychological resilience is connected with higher level of hardiness, control, and resistance to stress. Negative correlations were found between psychological resilience and spontaneous aggressiveness, neuroticism, irritability, depression (BSI 12), depressiveness (FPI), emotional instability, anxiety, shyness. The important factors of psychological resilience were identified by the study. High levels of challenge, personal growth, sociability, control, tendency to forgiveness, personal self-efficacy, commitment, self-acceptance, management of the environment increase the psychological resilience.
\end{abstract}

Keywords: Tendency to Forgiveness, Psychological Resilience, Hardiness, Control, Sociability

\section{Introduction}

According to many empirical studies, the concept of psychological resilience is one of the central concepts used to analyse the processes of adaptation and resistance to adverse environmental influences (Cleverley, Kidd, 2011; Fletcher, Sarkar, 2013).

Recently, the number of situations in which a person feels overstrained has increased significantly. Stressful situations usually make demands that go beyond the individual's ability to cope with them, even if they have the resources to do so. As a result, the individual shows a real inability to solve the problem, perceives own inability to cope with the demands of a stressful situation.

In connection with the continuation of the war in eastern Ukraine, the study of the peculiarities 
of psychological resilience of the personality as warnings to the negative consequences of a military conflict is a very important problem. The military conflict in eastern Ukraine has led to the destruction of public order, the social structure of communities, and the loss of contacts with close people.

Some studies have shown that psychological resilience allows an individual to positively adapt to the adverse consequences of difficult life situations, to protect against the development of traumatic stress and psychopathology, in particular depressive symptoms (Masten, 2014; Hu, Zhang, Wang, 2015; Gong, Yu, Schooler, 2018; Wu et al., 2020).

Lazarus (1993) in order to explain the meaning of the word "resilience" gave an example of the elasticity of metals with resilient bending of the metal and a rebound back instead of destruction under tension. Werner (1989) found that, under similar adverse conditions, two thirds of children already in adolescence demonstrated destructive behaviour: chronic unemployment, substance abuse, early childbirth. However, one third of children were not subject to such behaviour. According to Werner (1989), these children are characterized by healthy adaptation.

Masten (2014) identified 3 types of manifestations of psychological resilience: 1 ) people at risk, adapted better than one could expect; 2) the presence of positive adaptation, despite the stressful experience; 3 ) rapid recovery after a psychological trauma.

Rutter $(2012,2013)$ argued resilience as an interactive concept that involves the combination of a serious experience of risk events and a relatively positive psychological outcome, despite this experience. Garmezy (1991) defined psychological resilience as "not necessarily impermissible, impermeable to stress". Rather, the resilience reflects the ability to recover and support adaptive behaviour that may occur after the initial retreat or incapacity in response to the initiation of a stressful event. Garmezy (1991) claimed to be resilient, it is necessary to demonstrate functional adequacy as a criterion of resilient behaviour in stress. Functional adequacy refers to the maintenance of competent functioning, despite emotionality. Thus, indicators of psychological resilience, according to Garmezy (1991) there are prosperity, the maintenance of a state of well-being, in spite of difficulties, difficult situations, positive response to negative events, competent functioning in stressful conditions.

Bonanno and Mancini (2008), defining the concept of resilience, pointed to competence in stressful conditions, the ability to constructively reflect complex events.

It also discusses whether resilience is a skill, trait, or process.

Block (1980) considered the psychological resilience as a personality trait. Block used the concept of ego-resiliency as an individual-psychological property, the development of which protects people from the devastating effects on them problems of life; includes a set of characteristics such as ingenuity, agility, durability of character, flexibility of functioning in different conditions. Masten (2014), Silk, Vanderbilt-Adriance, E., Shaw, D. S., Forbes, E. E., Whalen, D. J., Ryan, N. D., Dahl (2007) and Luthar, Cicchetti, Becker (2000) proposed to consider resilience as a dynamic process, which is a continuous and active process of positive human adaptation in situations of crisis and crisis (or extreme) events, and situations, and which has an uneven dynamics of new forces and resources of recovery in conditions emergence of new risks.

Some studies have shown that the concept of psychological resilience describes the ability to overcome difficulties, to adapt positively, to function successfully (Luthar, Cicchetti, Becker, 20oo; Rutter, 2012; Ungar, 2004; Williamson, 2006; Gong, Yu, Schooler, 2018).

A review of modern scientific research shows that the construct of psychological resilience can relate to an individual, a family, and a community (Norris, 2008; Walsh, 2016; Tusaie, Dyer, 2004; Southwick et al., 2014; Scoloveno, 2016), namely their physical, psychological, and social characteristics.

We consider psychological resilience as an integrative feature of individual which manifests itself in ability to maintain a stable level of psychological and physical functioning in critical situations, to come out of such situations without persistent violations, to successfully adapt to adverse changes. The concept of psychological resilience describes the ability to overcome difficulties, to adapt positively, and to function successfully in critical situations.

In our opinion, psychological resilience is manifested through the following content-structural components: 1) commitment (defined as the belief that the person receives satisfaction from life, his 
own activities); 2) the need for knowledge (the personality is always open to new experience, a new impression); 3) control (the belief that the person chooses his own way in life, his own activities); 4) the ability to set realistic goals and carry out activities aimed at achieving them; 5) challenge (belief in the fact that knowledge obtained from positive or negative experience, contribute to the development of the individual); 6) ingenuity; 7) flexibility; 8) optimism; 9) cognitive complexity (the personality is oriented to the knowledge of complex phenomena, the personality likes complex and difficult tasks, shows interest in complex ideas); 10) altruism.

At present, there are few research tools in Ukraine to study the level of psychological resilience. In this context, the need to develop certain methodological tools is extremely important. We thus believe that development, validation, and adaptation of a reliable model of measurement for psychological resilience in the Ukrainian context constitute a valuable contribution to the repertoire of test instruments in psychology.

We believe that the propensity to forgiveness is an important factor in psychological resilience.

According to some empirical studies, people who have not learned to forgive have significantly more stress-related illnesses (Reed, Enright, 2006; Raj, Elizabeth, Padmakumari, 2016; VanderWeele, 2018). It has been found that self-forgiveness reduces the risk of post-traumatic stress disorder and suicidal ideation (Lijo, 2018).

Today, the content of the category of "forgiveness" is ambiguous. Forgiveness is considered by researchers as an action, act, response, abilities, personal disposition, mental state, characteristics of social units (North, 1987; Emmons, 2000; Mullet, Girard, 2000; Berry et al., 2005; Wade, Worthington, 2005).

In psychology, a stress-and-coping model of forgiveness (Worthington, et al., 200o; Strelan, Covic, 2006; Harper et al., 2014), procedural model of forgiveness (Fitzgibbons, 1986; Baskin, Enright, 2004), and the evolutionary model (McCullough, 2001) of forgiveness are presented.

Heider (1958) pointed out that forgiveness should be considered as a person's choice to give up vindictive behaviour. Enright (2001) noted that forgiveness requires the offended person to renounce anger and resentment. Worthington et al. (2000) determined that forgiving of the offender involves letting go of negative experiences such as anger, hatred, sadness, resentment.

Some studies have shown that forgiveness should be considered as a dispositional feature, partial manifestation, and result of the mechanisms of social cognition of a person, as the ability to forgive is based on awareness of own emotions and the ability to control them, as well as the ability and willingness to empathize with the offender (Mullet, Girard, 2000; Berry et al., 2005).

Emmons (2000) suggested that forgiveness be seen as a high-level personal construct in which individuals have the following characteristics: 1 ) the ability to be receptive to circumstances that reduce anger; 2) availability of emotion control skills; 3) empathy; 4) humility; 5) friendliness and desire to be in a harmonious relationship.

We see forgiveness as a process of a person's conscious rejection of resentment, anger, hatred, indignation, sadness caused by the unfair treatment of others, and the replacement of negative feelings with more neutral, and, finally, positive, such as compassion, pity, accompanied by positive thoughts about the offender and the termination of his conviction.

In our opinion, the phenomenon of forgiveness plays an important role in ensuring the mental health of the individual.

\section{Objectives}

The objectives of this study were to explore the features of the relationship between tendency to forgive and psychological resilience, to empirically determine the factors of psychological resilience.

\section{Hypotheses}

Such hypotheses formed the basis of the study design plan: 
$\mathrm{H1}$ : Psychological resilience is positively correlated with tendency to forgiveness.

$\mathrm{H}_{2}$ : Psychological resilience is positively correlated with hardiness, control, resistance to stress.

$\mathrm{H}_{3}$ : Psychological resilience is negatively correlated with spontaneous aggression, neuroticism, irritability, depression, depressiveness, emotional instability, shyness, anxiety.

$\mathrm{H}_{4}$ : Hardiness, sociability, tendency to forgive, personal growth, and personal self-efficacy are significant factors of psychological resilience.

\section{Research Methodology}

\subsection{Participants}

The participants were 615 Ukrainian students (female $=317,51.5 \%$; male $=298,48.5 \%): 313$ Ukrainian youthful students who receive the first higher education (female $=162,26.3 \%$; male $=151,24.6 \%$ ), aged between 19 and 23 years and 302 Ukrainian students who receive a second degree (female $=155,25.2 \%$; male $=147,23.9 \%$ ), aged between 24 and 56 years. Table 1 shows the distribution of the sample by gender and age.

Table 1. Sample distribution by gender and age

\begin{tabular}{|l|c|c|c|c|c|c|}
\hline \multirow{2}{*}{ Groups } & \multicolumn{2}{|c|}{$19-23$ years } & \multicolumn{2}{c|}{$24-56$ years } & \multicolumn{2}{c|}{ Total } \\
\cline { 2 - 7 } & № & $\%$ & № & $\%$ & № & \% \\
\hline Female & 162 & 26.3 & 155 & $\mathbf{2 5 . 2}$ & 317 & 51.5 \\
\hline Male & 151 & 24.6 & 147 & 23.9 & 298 & 48.5 \\
\hline Total & 313 & 50.9 & 302 & 49.1 & 615 & 100.00 \\
\hline
\end{tabular}

The sample of respondents was formed from 5 Ukrainian universities: Taras Shevchenko National University, Borys Hrinchenko University, M. P. Drahomanov National Pedagogical University, "KROK" University of Economics and Law, Kyiv National Linguistic University.

Data were obtained using tests, questionnaires, which were presented in individual form. Respondents' participation in the study was confidential and voluntary. Data were collected in accordance with the American Psychological Association's (2010) ethical principles and codes of conduct.

\subsection{Methods}

Trait Forgivingness (dispositional) Scale (the authors: J. W. Berry, E. L. Worthington, L. E. O'Connor, L. Parrott, N. G. Wade (Berry et al., 2005)) contains 10 items rated on a five-point Likert-type Scale of Frequency $(1=$ strongly disagree; $5=$ strongly agree). It was translated using double translation technique: from English to Ukrainian and from Ukrainian to English. The scale has been validated on a Ukrainian sample. The McDonald's omega for this study was .92.

Psychological Resilience Scale (PRS-11) (the author: S. Kravchuk). Psychological Resilience Scale contains 11 items rated on a seven-point Likert-type Scale of Frequency ( $1=$ absolutely wrong; 7 = quite right).

The McDonald's omega for this study was .89. The exploratory factor analysis (EFA) was performed on the Ukrainian sample. Retest reliability was verified by analysis of correlation between the first total score of the eleven-item Psychological Resilience Scale (PRS-11) and second total score of the eleven-item Psychological Resilience Scale (PRS-11) received at intervals of 7 weeks. We found higher the Pearson's correlation coefficient $(.79, \mathrm{p}<.001)$. The obtained correlation indicates a high retest reliability of the scale of psychological resilience. The results of examining model fit in the confirmatory factor analysis indicate good fit. The index of Normed Chi-Square ( $\left.\mathrm{x}^{2} / \mathrm{df}\right)$ is 2.614 , which indicates a good fit. The index of Root Mean Square Error of Approximation (RMSEA) is .067, which 
indicates reasonable error and acceptable fit. The index of Standardized Root Mean Square Residual (SRMR) is .062, which indicates good fit. The index of Comparative Fit Index (CFI) is .956, which indicates good fit. The index of Tucker-Lewis index (TLI) is .948, which indicates good fit.

The author performed EFA analysis in order to find a one-dimensional solution for scale of psychological resilience. Results provide an opportunity to see the indices to examine model fit in the confirmatory factor analysis: 1 ) Normed Chi-Square ( $\mathrm{x}^{2} / \mathrm{df}$ ), with 2 to 5 indicating good fit; 2 ) Root Mean Square Error of Approximation (RMSEA), with .05 to o.8 indicating reasonable error and acceptable fit; 3) Standardized Root Mean Square Residual (SRMR), with values less than .o8 indicating good fit; 4) Comparative Fit Index (CFI) and Tucker-Lewis index (TLI), with values above .9o suggesting good fit, according to Tabachnick and Fidell (Tabachnick and Fidell, 2013), Kline (Kline, 2015).

The scale of psychological well-being (the authors: C. D. Ryff, C. L. Keyes (Ryff and Keyes, 1995)) consists of six scales: 1 ) Positive Relationships (14 items, the McDonald's omega for this study was .91); 2) Autonomy (14 items, the McDonald's omega for this study was .90); 3) Management of the environment (14 items, the McDonald's omega for this study was .92); 4) Personal Growth (14 items, the McDonald's omega for this study was .89); 5) Goals in Life (14 items, the McDonald's omega for this study was .90); 6) Self-Acceptance (14 items, the McDonald's omega for this study was .92). The integral indicator is Psychological Well-being. The scale of psychological well-being contains 84 items rated on a six-point Likert-type Scale of Frequency $(1=$ absolutely disagree; $6=$ absolutely agree $)$. The McDonald's omega for this study was .91.

Freiburg Personality Inventory (the authors: J. Fahrenberg, R. Hampel, H. Selg) consists of twelve scales: 1) Neuroticism (17 items, the McDonald's omega for this study was .89); 2) Spontaneous Aggressiveness (13 items, the McDonald's omega for this study was .90); 3 ) Depressiveness (14 items, the McDonald's omega for this study was .90); 4) Irritability (11 items, the McDonald's omega for this study was .90); 5) Sociability (15 items, the McDonald's omega for this study was .92); 6) Stress Tolerance (10 items, the McDonald's omega for this study was .91); 7) Reactive Aggressiveness (10 items, the McDonald's omega for this study was .92); 8) Shyness (10 items, the McDonald's omega for this study was .90); 9) Openness ( 13 items, the McDonald's omega for this study was .92); 10) ExtraversionIntroversion (12 items, the McDonald's omega for this study was .91); 11) Emotional Instability (14 items, the McDonald's omega for this study was .92); 12) Masculinity-Femininity (15 items, the McDonald's omega for this study was .89). Freiburg Personality Inventory contains 114 items rated on a two-point Scale (agree, disagree).

Hardiness Test (the author: S. Muddy) consists of three scales: 1) Commitment (18 items, the McDonald's omega for this study was .91); 2) Control (17 items, the McDonald's omega for this study was .92); 3) Challenge (10 items, the McDonald's omega for this study was .90). The integral indicator is Hardiness. Hardiness Test contains 45 items rated on a four-point Likert-type Scale of Frequency (o $=$ not $; \mathbf{1}=$ rather no than yes; $\mathbf{2}=$ rather yes than no; 3 = yes). The McDonald's omega for this study was .91 .

Mental Health Outcome Measures (Depression and Anxiety (BSI - 12)) (the author: L. R. Derogatis (Derogatis, 2001) consists of two scales: 1) Anxiety (6 items, the McDonald's omega for this study was $.93)$; 2) Depression (6 items, the McDonald's omega for this study was .91). Depression and Anxiety (BSI - 12) contains 12 items rated on a five-point Likert-type Scale of Frequency ( $0=$ not at all; $1=$ a little bit; 2 = moderately; 3 = quite a bit; 4 = extremely).

Overall Self-efficacy Scale (the authors: R. Schwarzer, M. Jerusalem (Schwarzer and Jerusalem, 2010)). The scale measures the overall measure of the subjective assessment of personal performance. Overall Self-efficacy Scale contains 10 items rated on a four-point Likert-type Scale of Frequency $(1=$ absolutely wrong; 4 = quite right). The McDonald's omega for this study was .91.

\section{Study Design and Statistical Analysis}

All the statistical analyses were conducted in Mplus, version $7 \cdot 4$ (Muthen \& Muthen, 1998-2012) and IBM SPSS Statistics 21 Premium+AMOS. 
The roadmap of the present data analysis was planned to include five procedural steps.

First, reliability of measures was assessed by adopting McDonald's omega.

Second, the sample of respondents for normal distribution by Kolmogorov-Smirnov test was checked.

Third, the Pearson's correlation coefficient to test the features of the relationship between tendency to forgiveness and psychological resilience was investigated.

Fourth, the Pearson's correlation coefficients to test the features of the relationship between psychological resilience and individual psychological characteristics were identified.

Fifth, multiple regression analysis for the factors of psychological resilience was performed.

\section{Results}

The sample of study participants corresponds to the normal distribution: according to the KolmogorovSmirnov test for all variables the significance level $\mathrm{p}>0.05$. The significance level $\mathrm{p}>.05$ for all considered variables means that the given distribution does not differ statistically from the normal one.

Table 2 shows the relationship between psychological resilience and the tendency to forgiveness, and other individual psychological characteristics.

Table 2. The relationship of psychological resilience with individual psychological characteristics

\begin{tabular}{|l|c|c|}
\hline Indicators & Correlation coefficient & Significance level \\
\hline Tendency to Forgiveness & .43 & $\mathrm{p}<.001$ \\
\hline Resistance to Stress & .59 & $\mathrm{p}<.001$ \\
\hline Control & .62 & $\mathrm{p}<.001$ \\
\hline Hardiness & .71 & $\mathrm{p}<.001$ \\
\hline Anxiety & -.42 & $\mathrm{p}<.01$ \\
\hline Neuroticism & -.62 & $\mathrm{p}<.001$ \\
\hline Irritability & -.59 & $\mathrm{p}<.001$ \\
\hline Spontaneous Aggressiveness & -.64 & $\mathrm{p}<.001$ \\
\hline Depression (BSI - 12) & -.58 & $\mathrm{p}<.01$ \\
\hline Depressiveness (FPI) & -.54 & $\mathrm{p}<.01$ \\
\hline Shyness & -.42 & $\mathrm{p}<.001$ \\
\hline Emotional Instability & -.53 & $\mathrm{p}<.001$ \\
\hline
\end{tabular}

Analysis of correlations between psychological resilience and tendency to forgiveness, and other variables showed that all the correlations were statistically significant $(\mathrm{p}<. \mathrm{ol})$.

Positive correlation was found between psychological resilience and tendency to forgiveness, which means that higher level of tendency to forgiveness is connected with higher level of psychological resilience. Positive correlations were found between psychological resilience and hardiness, control, resistance to stress, which mean that higher level of psychological resilience is connected with higher level of hardiness, control, and resistance to stress.

Negative correlations were found between psychological resilience and spontaneous aggressiveness, neuroticism, irritability, depression (BSI - 12), depressiveness (FPI), emotional instability, anxiety, shyness, which mean that higher level of psychological resilience is connected with lower level of these variables.

Another analysis focused on identifying factors of psychological resilience. The method of multiple regression analysis was used to assess statistically significant predictors on the dependent variable, i. e. psychological resilience (see Table 3). 
Table 3. Coefficients for multiple regression analysis for dependent variable of psychological resilience

\begin{tabular}{|c|c|c|c|c|c|}
\hline \multicolumn{6}{|l|}{$\begin{array}{l}R=.712 ; R^{2}=.507 ; \text { Adjusted } R^{2}=.499 \\
F=17.632, p<.001\end{array}$} \\
\hline \multirow{2}{*}{ Model } & \multicolumn{2}{|c|}{ Unstandardized coefficients } & \multirow{2}{*}{$\begin{array}{c}\text { Standardized coefficients } \\
\text { Beta }\end{array}$} & \multirow{2}{*}{$t$} & \multirow{2}{*}{$p$ level } \\
\hline & $B$ & Standard error & & & \\
\hline (Constant) & 24.321 & 3.248 & & 7.253 & $\mathrm{p}<0.01$ \\
\hline Commitment & .323 & .044 & .293 & 2.674 & $\mathrm{p}<0.01$ \\
\hline Control & .332 & .052 & .302 & 2.826 & $\mathrm{p}<0.01$ \\
\hline Challenge & .443 & .058 & .364 & 3.235 & $\mathrm{p}<0.01$ \\
\hline Sociability & .338 & .153 & .312 & 2.927 & $\mathrm{p}<0.01$ \\
\hline Tendency to Forgiveness & .329 & .089 & .299 & 2.696 & $\mathrm{p}<0.01$ \\
\hline Personal Self-efficacy & .325 & .027 & .296 & 2.691 & $\mathrm{p}<0.01$ \\
\hline Positive Relationships & .054 & .049 & .075 & 1.086 & $\mathrm{p}>0.05$ \\
\hline Autonomy & .059 & .053 & .067 & 1.126 & $\mathrm{p}>0.05$ \\
\hline Management of the Environment & .093 & .053 & .128 & 1.992 & $\mathrm{p}<0.05$ \\
\hline Personal Growth & .346 & .084 & .334 & 3.125 & $\mathrm{p}<0.01$ \\
\hline Goals in Life & -.087 & .079 & -.152 & -1.312 & $\mathrm{p}>0.05$ \\
\hline Self-Acceptance & .265 & .087 & .203 & 2.291 & $\mathrm{p}<0.01$ \\
\hline
\end{tabular}

The regression model was found to be statistically significant and explained approximately $51 \%$ of the dependent variable. The following predictors were included in the model: tendency to forgiveness, commitment, control, challenge, sociability, personal self-efficacy, autonomy, management of the environment, personal growth, and self-acceptance.

High levels of challenge, personal growth, sociability, control, tendency to forgiveness, personal self-efficacy, commitment, self-acceptance, management of the environment increase the psychological resilience.

\section{Discussion}

The results of the empiric study provide interesting data that should be discussed.

There is a direct significant correlation between the indicator of propensity to forgive and psychological resilience $(\mathrm{r}=.43, \mathrm{p}<.001)$. In other words, persons who are prone to forgiveness are more able to adapt positively in stressful, crisis, or emergencies, more capable of constructive reflection of difficult events and competent functioning in difficult life situations.

Enright (2001) point out that positive effect of forgiveness is not associated with perceptions of forgiveness as a good or value, but with the direct "work of forgiveness", based on empathy and the reflexive component of social cognition.

According to a study by Abid, Shafiq, Naz, and Riaz (2015), there is a negative significant correlation between the level of forgiveness and neuroticism. Interestingly, this study also found a positive significant correlation between the level of forgiveness and conscientiousness, extroversion, openness, and agreeableness. In the study of Kaleta and Mrozs (2018) it was also shown that neuroticism negatively predicted the overall level of forgivingness and overcoming unforgiveness of self, others, and situations.

Researchers Kumar and Dixit (2014) found that there was statistically significant positive correlation among forgiveness, resilience, and gratitude.

There were revealed positive significant correlations of psychological resilience with hardiness ( $\mathrm{r}$ $=.71, \mathrm{p}<.001)$, control $(\mathrm{r}=.62, \mathrm{p}<.001)$, resistance to stress $(\mathrm{r}=.59, \mathrm{p}<.001)$ (see table 2 above). As $\mathrm{S}$. Muddy points out, hardiness is a system of human beliefs about themselves, the world, and the relationship with the world. Hardiness is a key personal characteristic that mediates the impact of stressors and prevents the emergence of internal tension in stressful situations. According to Muddy 
and Khoshaba (1994), hardiness reflects the psychological vitality and increased efficiency of personality, as well as an indicator of his mental health. Control as a "hardy" attitude motivates the individual to find ways to influence the results of stressful changes, as opposed to falling into a state of helplessness and passivity. Muddy and Khoshaba (1994) noted that a person with developed control chooses his own activities, his own way of life.

The positive significant correlations of psychological resilience with hardiness and control indicate that a person with psychological resilience is characterized by success in coping and overcoming adverse difficulties in life.

The positive significant correlation of psychological resilience with resistance to stress indicates that a person with psychological resilience is well protected from the influence of stress factors, based on self-confidence, optimism, and activity. Interestingly, the study of Gong, Yu, and Schooler (2018) found that there is a positive correlation between resilience and self-affirmation. According to the empirical study of Hu, Zhang, and Wang (2015), resilience is positively correlated with life satisfaction, subjective well-being, and positive emotions.

Divergent validity of the scale was confirmed by obtaining inverse significant correlations of psychological resilience with spontaneous aggression $(\mathrm{r}=-.64, \mathrm{p}<.001)$, neuroticism $(\mathrm{r}=-.62, \mathrm{p}<.001)$, irritability $(\mathrm{r}=-.59, \mathrm{p}<.01)$, depression (BSI - 12) $(\mathrm{r}=-.58, \mathrm{p}<.01)$, depressiveness (FPI) $(\mathrm{r}=-.54, \mathrm{p}<.01)$, emotional instability $(\mathrm{r}=-.53, \mathrm{p}<.001)$, shyness $(\mathrm{r}=-.42, \mathrm{p}<.001)$, anxiety $(\mathrm{r}=-.42, \mathrm{p}<.01)$ (see table 2 above).

The significant inverse correlations of psychological resilience with spontaneous aggression, neuroticism, irritability, and emotional instability indicate that a person with a low level of psychological resilience is characterized by insufficient self-regulation, unstable emotional state, manifested in frequent mood swings, increased excitability, prone to spontaneous aggression and anxiety.

In a study by $\mathrm{Hu}$, Zhang, and Wang (2015) it was shown that resilience is negatively correlated with indicators of mental ill-being, such as depression, anxiety, and negative emotions.

Scholars Mojrian, Homayouni, Rahmedani, and Alizadeh (2017) have proven that there is a significant and negative correlation between resilience with aggression and hostility.

Inversely significant correlations of psychological resilience with depression (BSI - 12), depressiveness (FPI), shyness, and anxiety indicate that a person with a low level of psychological resilience is characterized by the presence of depressive symptoms in the emotional state, behaviour, attitudes toward themselves and the social environment.

Inversely significant correlations between psychological resilience and shyness, and anxiety indicate that a person with a low level of psychological resilience is characterized by insecurity, anxiety, and a tendency to react stressfully to normal life situations by the passive-defensive type.

The positive statistically significant regression coefficients $(\mathrm{p}<.05)$ by multiple regression analysis shown on table 3 indicate that the greatest influence on psychological resilience is exerted by the following factors: challenge (standardized Beta coefficient $=.364$ ), personal growth (standardized Beta coefficient $=.334$ ), sociability (standardized Beta coefficient $=.312$ ), control (standardized Beta coefficient $=.302$ ), tendency to forgiveness (standardized Beta coefficient $=.299$ ), personal self-efficacy (standardized Beta coefficient $=.296$ ), commitment (standardized Beta coefficient $=.293$ ), selfacceptance (standardized Beta coefficient $=.203$ ), environmental management (standardized Beta coefficient $=.128$ )

Among the presented factors, challenge and personal growth have significant standardized Beta coefficients.

The results show that the important factors of psychological resilience are as follows:

1. Personality perception of life events as challenges and trials for oneself. According to S. Muddy, such a person sees life as a way to gain experience, both positive and negative, in order to develop themselves. The desire for simple comfort and security is seen as impoverishing the life of the individual.

2. Openness to new experiences, a sense of continuous development and realization of their 
potential, observation of improvements in themselves and their actions over time, changes in accordance with their own knowledge and achievements.

Sociability, control, propensity to forgive, and management of the environment are the important factors of psychological resilience. There are such conditions for the formation of psychological resilience as social activity, a pronounced need for communication and constant readiness to satisfy the need, propensity to forgive, sense of control (independent choice of own activity, the way of life, independent search of ways of influence on results of stressful changes), availability of competencies in environmental management, effective use of available opportunities.

Also, the formation of psychological resilience is influenced by personal effectiveness: belief in the effectiveness of own actions, optimistic thoughts about their own achievements, creating optimistic scenarios.

Commitment and self-acceptance are important factors of psychological resilience:

1. Harmonious interaction of the individual with the world around him, the possibility of perceiving himself as a significant and valuable person. This creates an opportunity to get involved in solving life's problems, despite the presence of stressors. Muddy and Khoshaba (1994) pointed out that commitment motivates self-development, promotes a healthy way of thinking and behaving. Such a person is self-confident and enjoys his own activities.

2. Positive attitude of a person to himself, who knows and accepts his various aspects and positively evaluates his past.

The above results, however, show one type of limitations. The limitation is that all variables were self-report. Future research designs should consider the opportunity to include also implicit measures, such as physiological parameters, in order to better understand the nature and boundaries of psychological resilience.

\section{Conclusion}

A direct significant correlation between tendency to forgiveness and psychological resilience was revealed. The higher level of tendency to forgiveness is connected with higher level of psychological resilience. The more a person is inclined to forgiveness, the more competently he (she) functions under stressful conditions.

Direct significant correlations of psychological resilience with hardiness, control, resistance to stress were revealed. The higher level of psychological resilience is connected with higher level of hardiness, control, and resistance to stress.

Negative significant correlations of psychological resilience with spontaneous aggression, neuroticism, irritability, depression (BSI - 12), depressiveness (FPI), emotional instability, shyness, anxiety were established. The higher level of psychological resilience is connected with lower level of spontaneous aggression, neuroticism, irritability, depression (BSI - 12), depressiveness (FPI), emotional instability, shyness, anxiety.

The important factors of psychological resilience were established. High levels of challenge, personal growth, sociability, control, tendency to forgiveness, personal self-efficacy, commitment, selfacceptance, management of the environment increase the psychological resilience.

The practical value of the study is that the results can be used in further research on the problem of resilience psychology and forgiveness psychology, as well as in psychological counseling in order to create conditions for constructive interaction of people in stressful situations. The scientific data will contribute to the creation of a training program aimed at the development of emotional stability, balance, and personal self-realization. The scientific data of the peculiarities of psychological resilience in youth and adults will contribute to the creating of a training program aimed at developing psychological resilience in youth and adults.

We see the prospect of further research in the theoretical and empirical study of psychological factors of resilience and forgiveness. 


\section{References}

Abid, M., Shafiq S., Naz I., Riaz M. (2015). Relationship between Personality Factors and Level of Forgiveness among College Students. International Journal of Humanities and Social Science, 5 (7), 149-154.

Baskin, T. W., \& Enright, R. D. (2004). Intervention Studies on Forgiveness: A Meta-Analysis. Journal of Counseling $\mathcal{E}$ Development, 82 (1), 79-90. doi: 10.1002/j.1556-6678.2004.tboo288.x.

Berry, J. W., Worthington, E. L., O'Connor, L. E., Parrott, L. I., \& Wade, N. G. (2005). Forgivingness, vengeful rumination, and affective traits. Journal of Personality, 73, 1-43.

Block, J. H. (1980). The role of ego-control and ego-resiliency in the organization of behaviour. Minnesota Symposium on Child Psychology, 13, 39-101.

Bonanno, G. A., Mancini, A. D. (2008). The Human Capacity to Thrive in the Face of Potential Trauma. Pediatrics, 121 (2), 369-375. doi: 10.1542/peds.2007-1648.

Cleverley, K., Kidd, S. A. (2011). Resilience and Suicidality Among Homeless Youth. Journal of Adolescence, 34 (5), 1049-1054. doi: 10.1016/j.adolescence.2010.11.003.

Derogatis, L. R. (2001). Brief Symptom Inventory (BSI) - 18: Administration, scoring and procedures manual. Minneapolis, MN: NCS Pearson.

Emmons, R. A. (200o). Personality and forgiveness. In M. E. McCullough, K. I. Pargament, \& C. E. Thoresen. Forgiveness: Theory, research, and practice (pp. 156-175). New York: Guilford Press.

Enright, R. D. (2001). Forgiveness Is a Choice: A Step-by-Step Process for Resolving Anger and Restoring Hope. Washington, DC: American Psychological Association.

Fitzgibbons, R. P. (1986). The cognitive and emotive use of forgiveness in the treatment of anger. Psychotherapy: Theory, Research, Practice, Training, 23 (4), 629-633. doi: 10.1037/hoo85667.

Fletcher, D., \& Sarkar, M. (2013). Psychological Resilience: A Review and Critique of Definitions, Concepts, and Theory. European Psychologist, 18 (1), 12-23. doi: 10.1027/1016-9040/aooo124.

Garmezy, N. (1991). Resilience in children's adaptation to negative life events and stressed environments. Pediatric Annals, 20, 459-46o, 463-466.

Gong, Z., Yu, L., \& Schooler, J. (2018). The Relationship between Resilience and Mental Health: the Mediating Effect of Positive Emotions. Applied Science and Innovative Research, 2 (3), 87. doi: 10.22158/asir.v2n3p87.

Harper, Q., Worthington, E. L., Griffin, B. J., Lavelock, C. R., Hook, J. N., Vrana, S. R., \& Greer, C. L. (2014). Efficacy of a workbook to promote forgiveness: a randomized controlled trial with university students. Journal of Clinical Psychology, 70 (12), 1158-1169. doi: 10.1002/jclp.22079.

Heider, F. (1958). The psychology of interpersonal relations. New York: Wiley.

Hu, T., Zhang, D., \& Wang, J. (2015). A meta-analysis of the trait resilience and mental health. Personality Individual Differences, 76, 18-27. doi: 10.1016/j.paid.2014.11.039.

Kaleta, K., Mrozs, J. (2018). Personality traits and two dimensions of forgivingness. Roczniki psychologiczne / Annals of psychology, 21 (2), 147-162.

Kline, R. B. (2005). Principle and practice of structural equation modeling. New York: Guilford Press.

Kravchuk, S. (2018). Hardiness as a factor of psychological resilience of youth in conditions of military conflict. Mental Health: global challenges, 32, 42. doi.org/10.32437/mhgcj.viii.19.

Kumar, A., Dixit, V. (2014). Forgiveness, gratitude and resilience among Indian youth. Indian Journal of Health and Wellbeing, 5 (12), 1414-1419.

Lazarus, R. S. (1993). From psychological stress to emotions: A history of changing outlooks. Annual Review of Psychology, 44, 1-21.

Lijo, K. J. (2018). Forgiveness: Definitions, Perspectives, Contexts and Correlates. Journal of Psychology $\mathcal{E}$ Psychotherapy, 8 (3), 342. doi: 10.4172/2161-0487.1000342.

Luthar, S. S., Cicchetti, D., \& Becker, B. (2000). The construct of resilience: A critical evaluation and guidelines for future work. Child Development, 71 (3), 543-562.

Maddi, S. R., Khoshaba, D. M. (1994). Hardiness and Mental Health. Journal of Personality Assessment, 63 (2), 265274 .

Masten, A. S. (2014). Global Perspectives on Resilience in Children and Youth. Child Development, 85 (1), 6-20. doi: $10.1111 /$ cdev.12205.

McCullough, M. E (2001). Forgiveness: Who Does It and How Do They Do It? Current Directions in Psychological Science, 10 (6), 194-197. doi: 10.1111/1467-8721.00147.

Mojrian, F., Homayouni, A., Rahmedani, Z., \& Alizadeh, M. (2017). Correlation Between Resilience with Aggression and Hostility in University Students. European Psychiatry, 41 (SI), 611. doi: 10.1016/j.eurpsy.2017.01.969. 
Mullet, E., Girard, M. (200o). Developmental and cognitive points of view on forgiveness. In M. E. McCullough, K. I. Pargament, \& C. E. Thoresen. Forgiveness: Theory, research, and practice (pp. 111-132). New York: Guilford Press.

Muthen, L. K., \& Muthen, B. O. (1998-2012). Mplus User's Guide: Statistical Analysis with Latent Variables (7th ed). Los Angeles, CA: Muthen \& Muthen.

Norris, F. H. (2008). Community Resilience as a Metaphor, Theory, Set of Capacities, and Strategy for Disaster Readiness. Journal of Community Psychology, 41 (1-2), 131-134.

North, J. (1987). Wrongdoing and forgiveness. Philosophy, 62, 499-508.

Raj, P., Elizabeth, C. S., Padmakumari, P. (2016). Mental health through forgiveness: Exploring the roots and benefits. Cogent Psychology, 3 (1), 1153817. doi: 10.1080/23311908.2016.1153817.

Reed, G. L., Enright, R. D. (2006). The effects of forgiveness therapy on depression, anxiety, and posttraumatic stress for women after spousal emotional abuse. Journal of Consulting and Clinical Psychology, 74 (5), 920-929. doi: 10.1037/0022-006X.74.5.920.

Rutter, M. (2013). Annual Research Review: Resilience - Clinical Implications. Journal of Child Psychology and Psychiatry, 54 (4), 474-487. doi: 10.1111/j.1469-7610.2012.02615.x.

Rutter, M. (2012). Resilience as a dynamic concept. Development and Psychopathology, 24 (2), 335-344. doi: 10.1017/So954579412000028.

Ryff, C. D., Keyes, C. L. (1995). The Structure of Psychological Well-Being Revisited. Journal of Personality and Social Psychology, 69 (4), 719-727. doi: 10.1037//oo22-3514.69.4.719.

Schwarzer, R., Jerusalem, M. (2010). The general self-efficacy scale (GSE). Anxiety, Stress \& Coping, 12, 329-345.

Scoloveno, R. (2016). A Concept Analysis of the Phenomenon of Resilience. Journal of Nursing E Care, 5 (4), 353. doi: 10.4172/2167-1168.1000353.

Silk, J. S., Vanderbilt-Adriance, E., Shaw, D. S., Forbes, E. E., Whalen, D. J., Ryan, N. D., Dahl, R. E. (2007). Resilience among children and adolescents at risk for depression: Mediation and moderation across social and neurobiological contexts. Development and Psychopathology, 19, 841-865. doi: 10.1017/So954579407000417.

Southwick, S. M., Bonanno, G. A., Masten, A. S., Panter-Brick, C., \& Yehuda, R. (2014). Resilience definitions, theory, and challenges: interdisciplinary perspectives. European Journal of Psychotraumatology, 5 (1), 25338. doi: 10.3402/ejpt.v5.25338.

Strelan, P., Covic, T. (2006). A Review of Forgiveness Process Models and A Coping Framework to Guide Future Research. Journal of Social and Clinical Psychology, 25 (10), 1059-1085. doi: 10.1521/jscp.2006.25.10.1059.

Tabachnick, B., \& Fidell, L. (2019). Using multivariate statistics (7th ed). Boston: Pearson Education.

Tusaie, K., Dyer J. (2004). Resilience: A Historical review of the construct. Holistic Nursing Practice, 18 (1), 3-8. doi:10.1097/00004650-200401000-00002.

Ungar, M. (2004). A constructionist discourse on resilience: Multiple contexts, multiple realities among at-risk children and youth. Youth and Society, 35 (3), 341-365. doi: 10.1177/0044118Xo3257030.

VanderWeele, T. J. (2018). Is Forgiveness a Public Health Issue? American Journal of Public Health, 108 (2), $189-190$. doi: 10.2105/AJPH.2017.304210.

Wade, N. G., \& Worthington, E. L. Jr. (2005). In Search of a Common Core: A content Analysis of Interventions to Promote Forgiveness. Psychotherapy: Theory, Research, Practice, Training, 42 (2), 160-177. doi: 10.1037/oo333204.42.2.160.

Walsh, F. (2016). Family resilience: A developmental systems framework. European Journal of Developmental Psychology, 13 (3), 313-324. doi: 10.1080/17405629.2016.1154035.

Werner, E. E. (1989). High-risk children in young adulthood: A longitudinal study from birth to 32 years. American Journal of Orthopsychiatry, 59 (1), 72-81. doi: 10.1111/j.1939-0025.1989.tbo1636.x.

Williamson, J. (2006). Psychosocial interventions, or integrated programming for well-being? Interventions, 4 (1), 425. doi: 10.1097/o1.WTF.oooo229526.63438.23.

Worthington, E. L. Jr., Kurusu, T. A., Collins, W., Berry, J. W., Ripley, J. S., \& Baier, S. N. (2ooo). Forgiving usually takes time: A lesson learned by studying interventions to promote forgiveness. Journal of Psychology and Theology, 28 (1), 3-20. Retrieved from: https://psycnet.apa.org/record/2000-15404-oo1.

Wu Y., Sang Z., Zhang X-C., Margraf J. (2020). The Relationship Between Resilience and Mental Health in Chinese College Students: A Longitudinal Cross-Lagged Analysis. Frontiers in Psychology, 11, 108. doi: 10.3389/fpsyg.2020.00108. 